\title{
Ocular Manifestations of Leprosy
}

\author{
JANE E. K. DORMAN \\ St Mary's Hospital Medical School, London, W.2
}

\begin{abstract}
In this survey of leprosy patients in Nepal, half the patients examined were found to have some ocular abnormality associated with leprosy. However, many did not have marked ocular signs, and might have been passed as normal in the absence of a more detailed examination. This paper is intended to demonstrate the importance of regular examination of the eyes of every leprosy patient.
\end{abstract}

\section{Introduction}

A 3-month elective period during the fourth year of the undergraduate medical course, at St Mary's Hospital Medical School, London, gave me the opportunity to investigate, at the suggestion of Mr Kennerley Bankes, the prevalence of ocular complications of leprosy in Nepal. Previous surveys in other areas of the world have given widely varying estimates of the number of patients so affected, the figures ranging from 6.3\% in Malawi (Ticho \& Ben Sira, 1970) to 100\% in Malaysia (Kirwan, 1955). Possible causes for this wide variation have been attributed to climate, race, and skin pigmentation. The proportion of cases of lepromatous to tuberculoid leprosy is also important, as ocular problems are more common in the former. A further factor is the method of examination used by the surveyor (Hobbs \& Choyce, 1971).

\section{The Survey}

\section{THE PATIENTS}

The patients studied were either out-patients at Shanta Bhawan Hospital, a general hospital in Kathmandu, or in-patients at Anandaban, a hospital for leprosy patients near Kathmandu run by The Leprosy Mission.

The age of the patients varied from 11 to 74 years; 32 of the 57 patients were aged under 30 years and 15 were under 20. The younger boys and girls were mainly in-patients at Anandaban so that they could learn the essentials of foot-care, and how to protect themselves from some of the crippling effects of the disease.

\section{THE EXAMINATION}

The age of the patient was first recorded and the face was examined for any obvious leprosy lesions. The eyelids particularly were examined in detail for any evidence of disease.

The patient was asked if he had noticed any watering or burning in his eyes. Then he was asked to shut his eyes gently and keep them closed for 10 seconds, 
to determine whether there was any lagophthalmos. Ocular movements were elicited and the condition of the conjunctiva, sclera, cornea, iris, and lens respectively was examined, using the hand-held combined loupe and slit-lamp (Hobbs, 1963). The fundi were examined, and finally corneal sensation was tested, using a fine strand of cotton wool and lightly touching the cornea.

\section{Results}

A summary of the results is given in Table 1 .

TABLE 1

\begin{tabular}{lr}
\hline Total number of patients examined & 57 \\
No facial or ocular symptoms & 25 \\
Facial, but no ocular symptoms & 4 \\
Ocular, but no facial symptoms & 14 \\
Both facial and ocular symptoms & 14 \\
\multicolumn{1}{c}{ Ocular symptoms } & \\
Total number with ocular symptoms & 28 \\
Burning or watering eyes & 22 \\
Lagophthalmos & 10 \\
Conjunctivitis & 1 \\
Diminished corneal sensation & 12 \\
Corneal ulceration & 5 \\
Anterior synechiae & 4 \\
Posterior synechiae & 1 \\
Keratic precipitates & 1 \\
Anterior chamber flare & 4 \\
Leprous deposits on iris & 1 \\
\hline
\end{tabular}

\section{FACIAL AND OCULAR SYMPTOMS}

Of the 57 patients 32 either complained of ocular symptoms or had visible facial or ocular lesions, and 28 of these had ocular problems.

\section{BURNING AND WATERING EYES}

In answer to direct questioning 22 of the patients admitted that their eyes were watering or burning: 9 of them had demonstrable lagophthalmos and 5 of these showed corneal ulceration. This is ulceration visible with the combined loupe and slit-lamp, without the use of fluorescin to stain the cornea.

The remaining patients included 9 with signs of old and active iritis, the signs including 4 with anterior synechiae, 1 with posterior synechiae, 5 with aqueous flare, and 1 with keratic precipitates. One of the 5 patients with aqueous flare had a visible pale yellow leprous nodule on the iris, near the pupil margin. Another patient who complained of watering eyes had conjunctivitis, and 3 were normal.

\section{LAGOPHTHALMOS}

Lagophthalmos was noted in 10 patients. In half of these there were no leprosy lesions on the face at all, and in one the lesion was on the upper lip, well away from the eyes; 9 of the 10 patients had complained of burning or watering eyes. 
DIMINISHED) ('ORNEAL SENSATION

Diminished corneal sensation was demonstrated in 12 patients, in 7 of whom it was bilateral; 8 of the patients had no visible facial lesions, though 3 of them had slight lagophthalmos. Altogether 5 patients suffered from both conditions, but in 2 there were obvious facial lesions.

\section{Discussion}

The results given above show that care of the eyes in leprosy is no small problem. About half the patients examined had ocular symptoms.

The complaint of burning or watering eyes is mentioned by Brand (1969) as being an important pointer to the presence of lagophthalmos and its complications. In many of the present cases it was the only symptom.

The fact that only 3 of the 22 patients with this symptom had normal eyes shows that it is extremely important to regard a report of watering eyes seriously. In many cases this may be the first sign of a potentially blinding complication. It is also especially important to treat iritis as soon as possible in order to prevent the severe complications of this condition.

Lagophthalmos and diminished corneal sensation should be discovered as soon as possible. These two conditions may occur together and with no signs to point to any abnormality in the eyes at all; these patients are especially vulnerable since the complications may in turn lead to corneal ulceration. During this process the patient may have complained only of mildly watering eyes, and that only on direct questioning. It is only too easy to observe deep ulcers on the feet, or clawing of the hands, and to be concerned only with these, while potentially blinding ocular symptoms and signs are overlooked or not elicited.

\section{Conclusions}

Half the patients seen in this survey in Nepal had some ocular pathology. The fact that many had no obvious facial lesions makes it even more important for all who treat leprosy patients to examine the eyes as a matter of routine.

All patients should be examined for lagophthalmos and the state of corneal sensation when first seen, regardless of the site of their skin lesions. These examinations should be repeated each time the hands and feet are checked. In addition, it is recommended that all leprosy patients should be asked routinely whether they have burning or watering eyes. Any patient who does so complain should undergo a full ophthalmic examination. This will rarely be a waste of time, and certainly will not be considered so by the patients themselves.

\section{Acknowledgements}

I should like to thank Mr J. Kennerley Bankes for his stimulating suggestions both before and after my elective period. Also I gratefully acknowledge the help and kindness shown to me by Dr J. Harris at Anandaban and for the interest he showed in my project. Finally, I should like to mention Mr I. Paine of Keeler Instruments Ltd, London, who very kindly lent me the instruments necessary for this survey, and then presented the Hobbs combined focal illuminator and slit bulb to The Leprosy Mission hospital at Anandaban. 


\section{References}

Brand, M. (1969). Watch Those Eyes. London: The Leprosy Mission.

Hobbs, H. E. (1963). Focally-illuminated hand magnifier. Brit. J. Ophthal. 47, 638.

Hobbs, H. E. and Choyce, D. P. (1971). The blinding lesions of leprosy. Lepr. Rev. 42, 131.

Kirwan, E. W. O’G. (1955). Ocular leprosy. Proc. Roy. Soc. Med. 48, 112.

Ticho, V. and Ben Sira, I. (1970). Ocular leprosy in Malawi. Brit. J. Ophthal. 54, 107. 